\title{
Assessment of the Dental Pipeline Program from the External Reviewers and National Program Office
}

\author{
Raymond A. Kuthy, D.D.S., M.P.H.; Marilyn Woolfolk, D.D.S., M.P.H.; Howard L. Bailit, \\ D.M.D., Ph.D.; Allan J. Formicola, D.D.S., M.S.; Kim C. D'Abreu, M.P.H.
}

Dr. Kuthy is Professor and Head of Preventive and Community Dentistry, University of Iowa College of Dentistry; Dr. Woolfolk is Professor, Department of Periodontics and Oral Medicine, and Assistant Dean for Student Services, University of Michigan School of Dentistry; Dr. Bailit is Professor Emeritus, Department of Community Medicine and Health Care, University of Connecticut School of Medicine and Co-Director of the Pipeline, Profession, and Practice: Community-Based Dental Education Program; Dr. Formicola is Professor of Dentistry and former Dean, College of Dental Medicine, Columbia University and Co-Director of the Pipeline, Profession, and Practice: Community-Based Dental Education Program; and Ms. D’Abreu is Deputy Director of the Pipeline, Profession, and Practice: Community-Based Dental Education Program, Columbia University. Direct correspondence and requests for reprints to the following for each section of this chapter: section 1, Dr. Raymond A. Kuthy, University of Iowa College of Dentistry, N337-2 DSB, Iowa City, IA 52242-1010; 319-335-7201 phone; 319-335-7181; raymond-kuthy@uiowa.edu; section 2, Dr. Marilyn Woolfolk, University of Michigan School of Dentistry, 1011 North University Avenue, Ann Arbor, MI 48109-1078; 734-763-3313 phone; 734-647-6805 fax; winder@umich.edu; and section 3, Dr. Howard L. Bailit, Department of Community Medicine and Health Care, School of Medicine, University of Connecticut, 260 Farmington Avenue, Farmington, CT 06030; 860-679-5487 phone; 860-679-5463 fax; bailit@nso1.uchc.edu.

Key words: underrepresented minority recruitment, community-based dental education, curricular revisions, extramural clinical rotations, practice plans, dental health policy, sustainability

Editors' Note: The evaluation of the Pipeline, Profession, and Practice: Community-Based Dental Education program has benefited greatly from input from the external reviewers of this report and the National Program Office (NPO) of the Pipeline program. The external reviewers (Dr. Raymond A. Kuthy and Dr. Marilyn Woolfolk) have painstakingly reviewed and critiqued drafts of every chapter of the report. The NPO has supported the work of the National Evaluation Team (NET) in providing open access to the workings of the program, cooperating in data collection efforts, encouraging the Pipeline schools to participate in the evaluation efforts, and providing sage advice and counsel regarding the evaluation analyses and interpretations. While striving to provide an independent, objective, comprehensive, and understandable evaluation of the Pipeline program, the NET felt substantially supported in its efforts by the external reviewers and the NPO - even if, for better or worse, the NET did not always follow their advice. Of course, despite the best efforts of the external reviewers and the NPO, all remaining errors of commission, omission, and interpretation in this report must remain the responsibility of the NET authors. Because of their extensive knowledge of the Pipeline program and their good efforts to improve the evaluation, this report includes independent assessments of the program and lessons learned from the Pipeline evaluation provided by the external reviewers and the NPO.

\section{Response to the Pipeline Evaluation}

\author{
Raymond A. Kuthy, D.D.S., M.P.H.
}

$\mathrm{T}^{\mathrm{s}}$ he Robert Wood Johnson Foundation (RWJF) and The California Endowment (TCE), along with each of the participating academic dental institutions, are to be commended for such a monumental undertaking in dental education. While both foundations have undoubtedly embarked on projects within other educational disciplines, this was the first major national dental curriculum initiative in quite some time. While some may view this program to have been a high-risk experiment for a dental curriculum that many consider jam-packed, its findings could portend other significant changes to address 
populations who are at higher risk for oral diseases. Hopefully, this is but the first step in developing new educational models that prepare students to meet the public's needs.

Dental education has traditionally been an "inhouse" venture for dental schools, with little latitude for students to provide care at community sites. Thus, the Pipeline endeavor generally required each institution to reassess its mission and decide whether access to care is part of its core mission. Regardless of any school's answer to that question, curricular change is somewhat problematic and time-consuming even when participating groups are in agreement. Each of the case studies in this report provides insight into the internal dynamics for curricular change in the participating institutions and how each addressed the steps necessary to achieve its goals and objectives. Such insight is quite useful because most of us in dental education have limited knowledge about the curricular dynamics of institutions other than our own. While not every dental school progressed at the same rate, such a major curriculum change allowed for healthy discussions among the faculty members in each institution.

As with any project of this magnitude, there were successes, some shortcomings, and several questions that beg for answers. In my opinion, the most notable success stories of this program included the following: the substantial increase in educational opportunities for underrepresented minorities (URM) within the dental profession; the movement of dental schools in reaching out to communities of substantial unmet oral health need, linking their educational and service goals; the development of community-based education curricula, even though it took much longer to achieve at some institutions than others; the establishment of short pipeline programs (predental clubs, summer enrichment, postbaccalaureate programs, special mentoring, etc.) to assist students in being competitive for dental school admission; and the development of either new extramural rotations or building a greater capacity for offsite student opportunities by those institutions that already had some established extramural activities.

One of the unanticipated accomplishments was the formal and informal networking that resulted from participation in the Pipeline program. Representatives from participating schools met on several occasions to help define the process, discuss how to achieve institutional goals and objectives, and share ideas on common educational, research, and service issues. Such opportunities can only foster bonds that should make each institution stronger. Probably the greatest unplanned achievement (at the outset), however, was the degree of collaboration by the California dental schools in using economies of scale to develop a recruitment scheme that could serve as a model for other regions of the country. In the case studies, many dental schools implied that they had insufficient numbers of qualified URM candidates within their own state; thus, many dental schools were URM importers, many recruiting from the same undergraduate programs. Thus, cooperative recruitment ventures could have a very positive impact for the participating dental schools and the profession as a whole.

The most obvious shortcoming of the program was that several institutions were unable to achieve the goal of having students participate for sixty days, on average, in extramural rotations. Nonetheless, each school was able to initiate viable extramural programs, albeit somewhat different in length and objectives than other institutions. Sixty days was a lofty goal for institutions that did not have the necessary infrastructure at the start. Logistic difficulties, at minimum, could have been anticipated for dental schools that had little if any experience with developing memoranda of agreement with local, state, regional, or federal agencies. Collectively, these institutions increased the number of offsite locations by 69 percent (from 204 to 344) from FY2003 to FY2007; however, this doesn't take into account all of the other sites in which a relationship was initiated but not consummated with an agreement. The lesson learned is that developing such an infrastructure takes a considerable amount of time to develop and nurture.

Somewhere along the way, the original goal of recruiting underrepresented minority/low-income students was shortened to include only the former group. While I understand the difficulties in accomplishing too much during this relatively short project period, "The number one barrier reported by administrators, faculty members, and students to being recruited to a particular school and into dentistry generally is a financial one" (see Chapter 7 of this report ${ }^{1}$ ). This point is exacerbated because there is acknowledgement that there is little overlap between underrepresented minority students and students from low-income families (see Chapter $6.1^{2}$ ).

In my opinion, the other deficiency of this program can been categorized as definitional. That is, each institution may have had a slightly different interpretation of commonly used terms (patient-cen- 
tered, underserved, what constitutes an extramural rotation, etc.). Likewise, dental schools may have used somewhat different metrics in measuring various process issues (patient counts, dental service counts, number of days that students served at an extramural location, etc.). Realistically, there needs to be some allowance for local interpretation. However, admonition for caveat emptor must be raised when strict adherence to one definition is not used by all. While this should not diminish the general findings from this program, readers should understand that some of the information is not as reliable as others.

This project generated many hypotheses, many of which are addressed in this report. It also raised other substantial questions that should be the focus of future research. Examples include the following: are dental schools with formal recruitment agreements with feeder institutions more or less likely than other dental schools to recruit URM students to their dental schools; will Pipeline institutions have substantially different curricula in five years than non-Pipeline institutions; does the length of service of the clinic supervisor at the extramural site have an impact on students' educational experience; is there a difference in student evaluations between extramural faculty who have some form of calibration by dental school faculty versus those who have minimal or no calibration; are students who participate in longer extramural rotations more clinically productive when they return for the remainder of their senior year than those with shorter rotations; are there differences in the amount of care provided by those who participate later in the senior year than those students who participate earlier; are students who participate in longer extramural rotations more likely to be sensitive to the overall needs of the community than those who have minimal time commitment at one facility; is there an unreasonable expectation for URM/LI students to actually provide a substantial amount of dental services to the traditionally underserved; will majority students be less likely to treat the traditionally underserved because they are of the opinion that others are being educated to serve this population; what is the impact of longer-term pipeline strategies (working with elementary and secondary schools) in increasing URM applications to dental schools; and is there a difference between those institutions that had a mandatory extramural rotation versus those that had a capstone experience for a select number of senior students.

Regardless of this incomplete list of research questions, the real impact of the program upon the public will not be known until several years from now, when it can be determined whether these graduates 1) actually devote a substantial proportion of their practices in serving those in most need for dental services and/or 2) learned valuable clinical and life experiences by participating at these extramural sites. Evidence thus far would seem to indicate that students within the Pipeline program are no more likely to provide substantial amounts of dental services to underserved patients than students from non-participating institutions.

There is an adage that "you can't fix with statistics what you bungled by design." The foundations were prescient in developing an evaluation component (the NET) to determine if three Pipeline objectives (increase recruitment and retention of underrepresented minority and low-income students; revise didactic and clinical curricula to support community-based educational programs; and establish community-based clinical education programs that provide dental students and residents with sixty days of experience in a patient care environment) were met. While any quasi-experimental design is not perfect (i.e., there is a threat to validity because of the selection process) and it will not provide the answers to many questions, the NET demonstrated that it spent many hours in the development of its instruments and yet the evaluation process was adaptable enough to address some evolutionary changes. NET constructed an evaluation process that adds credibility to its findings. The evaluation team should be commended for the inclusion of a qualitative component, along with the more traditional quantitative analysis. The interviews and focus groups provide perspectives that would not be apparent if only quantitative analyses were performed. Several of the findings were intuitive, whereas others may not be as clear-cut as was anticipated. The descriptive findings about the extramural rotations provide valuable additions to the dental literature. Importantly, the evaluation team developed several regression models that used contextual environment and communitybased dental education variables, along with student characteristics. Establishing such a well-conceived and consistent statistical approach provides more confidence in the findings.

I freely admit to having a bias toward having dental students involved in community-based educational experiences. However, my partiality goes beyond minimum involvement within the community. Student experiences need to go beyond driving in and out of a community for short periods of time and pro- 
viding limited dental services. Understandably, these extramural programs take a considerable amount of time to reach maturity. Moreover, clinical services are the primary reason for students being at these offsite locations. However, just as we should not lose sight of the "mouth being part of the body," we also need to realize that clinical services shouldn't be the only student activities while on these rotations. There must be an increase in student participation in community activities (attending health fairs, educational talks, attendance at community meetings, etc.), so that students understand the contextual relationship of oral health for members of this community. Currently, there seems to be very little emphasis about having the students understand (via participation) the environment in which they are providing clinical services. How are future practitioners going to make informed decisions about either working in a similar environment or their willingness to care for those most needing our assistance unless they have a better appreciation for the role of oral health within a community? Moreover, community decision makers will appreciate dental school efforts to understand issues that have an impact on the local community. Such networking will be important as institutions look to other agencies for financial support to sustain community-based programs.

A few other issues are worth mentioning for consideration and discussion. First, it is admirable that these institutions initiated or amplified some of the cultural competence experiences in the classroom or seminar setting. We all need constant reminders about sensitivity to cultural issues. Likewise, we all could benefit from refinement in our communication skills. However, dental schools should not be the starting point (nor the end point) for these efforts. Dental schools must be ready to adapt so that we are able to go beyond the minimum expectations in having our students ready to interact with the next generation of patients. Second, the decreased URM enrollment numbers for the final years of the project were discouraging. Further inquiry is warranted in determining whether this is an aberrant statistical result or it might be partially attributable to a reduced effort by faculty and staff near the end of the funding period. Third, while the findings indicate that faculty members thought the Pipeline program did not have an influence on external policy involvement by their dental school, such changes are rarely immediate and cannot be achieved without substantial involvement with policymakers on a regular basis. We should be encouraged that The California Endowment is willing to take the longer view in this regard and is helping the California schools to work at the national and state levels in finding solutions for financial sustainability of their programs. Fourth, there remains a paucity of URM faculty role models at most dental schools. While we are all acutely aware of the national need for qualified faculty, this does not diminish the point that having suitable role models increases the likelihood of attracting URM students to many dental schools. Fifth, there should be further research in determining whether or not the type of community agency (federally qualified health center, community hospital, local health department, etc.) has an influence on either the educational experience or students' perceptions about caring for different types of underserved populations. Certainly, the organization's philosophy of dental care may be quite different from that taught at the dental school. Ongoing discussions between the home institution and extramural faculty will allow varying philosophies to coexist. Students also experience the opportunity to discuss these philosophies as they develop their own philosophy of dental care. Sixth, the cost of a dental education may preclude a considerable number of talented individuals from entering our profession. While this project principally addressed some issues relating to the education of URM students, less effort was devoted to inclusion of students from economically challenged families. We need to be cautious about including these two groups in the same breath.

Dental education has moved forward by participating in this momentous project. Moreover, the inclusion of a descriptive narrative about each institution's process in curriculum design and the qualitative and quantitative analyses of several key questions concerning these curriculum changes allows for benchmark findings that will be discussed for years to come. 


\title{
Response to the Pipeline Evaluation
}

\author{
Marilyn Woolfolk, D.D.S., M.P.H.
}

$\mathrm{T}$ he aims of the Pipeline program were ambitious, and the Robert Wood Johnson Foundation and The California Endowment are to be commended for investing in such a worthy cause. These foundations and others took a bold step and mounted a substantive response to the challenges of addressing the critical shortage of oral health care for the underserved and disadvantaged populations that were outlined in the U.S. surgeon general's report on oral health ${ }^{3}$ and the Institute of Medicine's report on unequal treatment. ${ }^{4}$ The Sullivan Commission report, Missing Persons: Minorities in the Health Professions, ${ }^{5}$ provides even more evidence and motivation to diversify the health professions workforce and change the culture of our health institutions. The Sullivan Commission report cited the changing demographics of our nation and the need to keep pace with these demographics by increasing the diversity of the workforce and changing the culture of health professions schools. In perfect synchrony, the Pipeline program has identified specific goals and provided the financial leverage and positive energy to generate curriculum change, expand the educational setting to include more days in community-based clinics, address unmet need, and recruit URM students to the profession.

The Pipeline program has pushed us to change our vision of the profession and our vision of the preparation of a dental health professional that could lead to a new era of excellence in health care for a broader spectrum of the population. In the process, it appears that some Admissions Committee approaches at individual dental schools were revised and that methods of assessing applicants using "whole-file" review of cognitive and noncognitive factors may have gained some traction. The latter strategy is one that absolutely must gain a bigger toehold in admissions processes universally to increase enrollment of URM students at a time when anti-affirmative action sentiment and ballot initiatives prevail and threaten to expand into more states beyond Texas, California, Washington, and Michigan.

One notes that the large increases ( 77 percent) in the applicant pool of URMs yielded only a small increase (10 percent) in the total number of enrolled students and worries that some of the gains at Pipeline schools may be temporary as the numbers peaked in
2006 and were already slipping in the last program year of 2007 . One questions whether the gains reported are perhaps a redistribution of the most qualified students who may have previously chosen to attend other schools. The difference in actual enrollment compared to the swell of applications suggests that obstacles of getting past the admissions gatekeepers are still the biggest challenge to making significant increases in the numbers of URM students as we intend. Until we change our markers for successful admission that heavily weigh standardized tests and discount noncognitive factors, our enrollment goals related to diversity may not be achieved. Additionally, we should extend our interest to the environment of support so these students feel welcome and thrive. There will need to be greater effort to ensure that the climate for the students is substantially improved and monitored once they are enrolled because URM students are visible and can easily be marginalized in some dental school environments.

Given the comprehensiveness of the effort expended by the National Program Office (NPO) and the Pipeline grantees, it still seems that continued progress toward the goal of increasing URM enrollment is tenuous at best. Since the beginning of the Pipeline program, two new dental schools have opened and more are expected to come into operation, so as we build capacity, we certainly should be capable of enrolling more students from minority and disadvantaged backgrounds. At the same time, attention should also be focused toward easing the financial burden and facilitating access to health professions schools with hefty scholarship support and loan forgiveness options; the Pipeline program has provided impetus and support for such initiatives.

While not a direct focus of the Pipeline grants and without any explicit intervention component, the potential to impact practice plans of graduates was expected to be a tangential outcome of the program. It does not, however, seem to have impacted practice plans to the extent one would consider meaningful. Few students indicate plans to serve in a community clinic or in government service after graduation. This result is not surprising because the economic realities of establishing oneself professionally and paying off 
undergraduate and dental school loans do not give new graduates much latitude to respond to a social conscience or pursue practice plans that might leave them financially further disadvantaged.

The evaluation efforts for the Pipeline program have been comprehensive and have looked at many dimensions of a complex issue. While it is impressive to be able to report large percentage increases in numbers of applicants, the actual increase in terms of individual enrollees from URM groups, particularly African Americans (10 percent or thirteen enrollees) and American Indians ( $<10 \%$ and one enrollee), is modest at best. In practical terms, however, the achievements of the project, as I see it, lie not only in the tangible or measurable results but in other results that are more difficult to measure. These include the extent to which awareness of the stagnant trend in enrollment among URMs and the role of social responsibility in dental schools has been raised. As a consequence of the Pipeline grants and publicity around their existence, there appears to be a peer pressure effect. The concept of expanding community-based education seems to have permeated the educational fabric of all dental schools and to have set an expectation of providing increased access to care and improving health outcomes for patients. The cross-site comparisons reveal that, with the right incentives, all Pipeline schools showed some will and capacity to change their curricula to accommodate community-based educational experiences. The increase in the mean number of days for extramural rotations gives one confidence that many of the schools are excited to put students in an environment that can adequately serve as an extension of their classroom or clinical training, provide quality health care to deserving populations, and help respond to the oral health care access crisis.

The beauty of the Pipeline program for the socially responsible is that if even one more person was cared for than would have otherwise gotten care, the project has been a worthy endeavor. In an environment in which only two of the fifteen Pipeline schools had an explicit mission to provide care to the underserved when the program started, one gets an inkling of the relative priority or lack thereof placed on this aspect of dental education prior to the initiation of this project. It's not clear from the report how many Pipeline schools have subsequently modified their missions, but the importance of such an effort as an undeniable responsibility of dental schools has been highlighted. I agree with the comments of those who expect that, as a result of this initiative, all dental schools have grown in their willingness to recognize and assume more responsibility for ensuring greater access to oral health care for the most vulnerable of our communities and solving dental access disparities. The speed toward this goal may be hampered by financial or other pressures on schools, but incremental achievements can still be meaningful.

Many dental school graduates that I speak to are discouraged from seeking positions where they might be able to help the underserved because of the high level of indebtedness they face as a result of attending professional school. It is simply unfair to impose all the responsibility on those with perhaps the biggest hearts and the fewest financial resources. If we can learn more about what factors are associated with a greater level of satisfaction among the dentists and physicians who work in community-based health entities and duplicate those factors in all sites, that might encourage students of all backgrounds to pursue practice in these locations in greater numbers. With increased respect from all practitioners and better marketing by educators and the professional community, quality practitioners can be motivated to participate and thrive in organizations that emphasize social responsibility and to become advocates for programs and resources that address the needs of vulnerable populations.

As for dental schools, until we change our current markers for success (e.g., National Board scores, number of research grants secured and publications written, clinical productivity, and revenue generated), the core values that undergird increased access to care will be marginalized. Having been in dental education for more than a quarter of a century, I have watched the dilution of community dentistry efforts in the curriculum, seen Departments of Community Dentistry lose visibility as they are absorbed into larger departments, and worried that the pedagogy that supports community dentistry and public health practice is at risk of disappearing. I have also seen the erosion of the depth of public health philosophy and practice being taught in the dental school curriculum and now the elevation of them as a priority as external dollars flood the marketplace. At the end of the day, if our commitment as a dental education community has in any way been reshaped to reach out to the population to solve the disparities problem and if our commitment to the principles of social justice and inclusion in higher education and health care services has been reborn, then we have indeed been well served by the comprehensive platform of the Pipeline, Profession, and Practice: Community-Based Dental Education program and its implementation. 


\title{
Response to the Pipeline Evaluation: The National Program Office Perspective
}

\author{
Howard L. Bailit, D.M.D., Ph.D.; Allan J. Formicola, D.D.S., M.S.; \\ Kim C. D'Abreu, M.P.H.
}

$I^{t}$ is important to place the Pipeline program in context with the time it began and the state of the art regarding dental education and access issues. In his comments, Kuthy stated that "dental education has traditionally been an 'in-house' venture for dental schools, with little latitude for students to provide care at community sites" and that "the Pipeline endeavor generally required each institution to reassess its mission." In her comments, Woolfolk stated that the program "has pushed us to change our vision of the profession and our vision of the preparation of a dental health professional that could lead to a new era of excellence in health care for a broader spectrum of the population" and that "in the process, it appears that some Admissions Committee approaches ... were revised and ... 'whole-file' review of cognitive and noncognitive factors may have gained some traction," overcoming some of the anti-affirmative action sentiment in the country. We concur with their overall comments.

The Pipeline program was conceived and launched shortly after the surgeon general's report on the oral health of the nation ${ }^{3}$ and just prior to the release of the Institute of Medicine and Sullivan Commission reports on the lack of diversity in the health professions. ${ }^{4,5}$ There was nothing on the horizon at the time to take these nationally respected reports and translate them into programmatic advances in dental education. We (the NPO) realized that the Pipeline program would be pushing the envelope, as its goals (see Chapter 2 of this report ${ }^{6}$ ) were far-reaching. Thus, the fifteen schools would set the pace in a new direction for dental schools - one that was responsive to societal issues. We fully expected that in five years the project would "get the ball rolling" and that the ambitious goals set would be a benchmark, but that not all schools would achieve them. In this respect, the program was more successful than we expected, since the majority of the schools did make major progress and, equally importantly, many non-Pipeline schools have been influenced by the program and are now moving to community-based education and the recruitment of a more diverse student body. The Pipe-

line program also showed that the major foundations can impact the manner in which a health profession responds to the needs of society.

The specific lessons we have learned from directing the Pipeline program are divided into two broad categories: structural and operational.

\section{Structural Lessons}

The structural lessons are related to the basic design of the study and include 1) the interventions chosen to decrease access disparities and 2) the schools selected to participate in the project. First, it is essential to have a basic understanding of the external and internal forces acting on dental schools. For the interventions to be successful and for program sustainability, the interventions must support rather than contravene these forces. As an example, we knew that dental schools were under significant financial pressure because of the loss of federal and state support. We also recognized that schools could increase class size to capture more tuition dollars. Because they did not have funds to build additional operatories to accommodate more students, they would have to send more students to community clinics and practices. We were correct in these assumptions, and several Pipeline schools expanded their community service-learning programs for this reason. As another example, we knew that some clinical faculty members would have reservations about sending students to community clinics. We were also aware that most students find it difficult to deliver care in dental school clinics because of the long waits for supplies and instructors, the lack of dental assistants, etc., and that they preferred to work in community clinics where they had access to trained clinical and administrative staff. As such, we were not surprised that students were a major force in convincing faculty of the value of community clinic rotations.

Second, we selected for the Pipeline program a few schools that had well-established and successful URM recruitment and/or community servicelearning programs. We did this for two reasons: we 
recognized that if high prestige schools were running successful programs, it would be easier to convince the other schools to move in the same direction; and we wanted a few schools with a lot of technical expertise in running recruitment and service-learning programs because we could build on this expertise in helping the other schools with their programs. For these reasons, we selected the University of North Carolina at Chapel Hill and the University of California, San Francisco. Finally, by including two historically black schools, Howard University and Meharry Medical College, the program gained from their unique vantage points in understanding the critical role that race and ethnicity play in recruiting students of color. These dental schools were a major factor in the success of the program.

\section{Operational Lessons}

We divide the primary operational lessons learned into two categories: general and programmatic. The general lessons relate to leadership, program administration, and communications. The programmatic lessons relate to running the community-based education and URM recruitment programs.

Regarding the general lessons, we observed that effective leadership from deans and associate deans was critical to bringing about the complex changes in admissions and curriculum required by the program. The more engaged the top leadership was in supporting needed changes, the more successful schools were in reaching Pipeline objectives. Another leadership issue was the role of the Pipeline principal investigators/project directors at each of the funded schools. We found that these individuals needed to be trusted members of the faculty and well respected by the administration to effect the necessary changes in school policies and operations. We found that excellence in program administration was an essential component of successful programs. That is, schools had to make a major commitment to build the program infrastructure (e.g., people, technology, business processes) to run effective programs. Having good intentions and ideas was important, but they were no substitute for solid operations.

We learned early on that good communications among the NPO, schools, and external stakeholders were critical success factors. We encouraged interactions among program directors and faculty so they could learn from each other. These interactions were built into the annual and other project meetings and activities. We made a special effort to be in frequent contact with participating schools through site visits, conference calls, and general meetings. We were able to carefully monitor each school's progress and to assist and encourage them to overcome operational, economic, and political challenges. The NPO was well positioned to know how one school could assist another and how to use program resources to solve problems.

Finally, we knew that the Pipeline project had high visibility within the dental practice, education, and public health communities and that the success of the program depended on keeping these stakeholder organizations informed and supportive. We used many different vehicles for this communication, but personal meetings with key people and organizations were essential. This communication was well worth the effort, because it resulted in broad acceptance of the Pipeline program.

Regarding the programmatic lessons, we observed that students were much more productive in community health centers than in traditional dental school clinics. Further, we received many reports that students enlivened the community clinic environment and were well accepted by patients. We learned that students must earn credit for services provided in off-site facilities. Concerned about graduating, they cannot be expected to spend substantial time in community clinics without earning credit.

In terms of recruitment of URM students, we found that dental schools' and their parent universities' mission statements need to include a supportive statement on student diversity. Also, we observed that to increase URM student enrollment and applicants, it is essential to increase the percentage of URM applicants who receive an interview. We found that successful URM recruitment programs require a hands-on approach. Specifically, schools need to be in contact with URM applicants during all phases of the application and admissions process. This is because many URM students do not get adequate guidance from college advisors. These lessons confirm many of the findings and observations from the IOM report In the Nation's Compelling Interest ${ }^{7}$ and the Sullivan Commission report. ${ }^{5}$

We are convinced that summer enrichment and postbaccalaureate programs are very valuable. The former increase college students' interest in the dental profession and make them more competitive applicants. The latter program often results in 80 percent of students enrolling in dental school.

We are convinced that admission committees need to consider all candidate attributes, so there is 
balance between quantitative (e.g., DAT and GPA scores) and qualitative (e.g., motivation, life experiences) performance measures. This is known as the "whole file review" of candidates.

Finally, we observed that schools need to pay attention to their internal climate for diversity. This is especially true for schools that lack a critical mass of URM students. We learned that there are specific ways for schools to undertake cultural audits and to use this information to make URM students feel welcome.

\section{Differences in Outcomes Data Between the NET Study and NPO Reports}

This very thorough and independent evaluation of the Pipeline program will assist others in understanding the important details of how these schools went about achieving their results. In viewing the overall outcomes of this important national initiative, it is important to recognize some differences in how the NET and the NPO reported outcomes on two major components of the program: the increase in URM students and the time senior students spent in community-based facilities. In Chapter 7 of this report, the NET reported that URM student enrollment increased 27 percent between 2003 and 2007. ${ }^{1}$ The NPO reported a 57.7 percent increase. The reason for this discrepancy is that the NPO measured the increase only in the majority schools: Howard and Meharry were not included in the count, as they were not expected to increase URM enrollment.

Regarding days spent in community clinics, the NET reported a mean increase from sixteen to thirtynine days. The NPO calculated the change from ten to fifty days. These differences arise because the NPO did not give schools baseline credit for time spent in clinics that were not patient-centered. Also, the NET did not include the time spent by California pediatric and general dentistry residents in community clinics as required by The California Endowment. We appreciate that these are technical details on the way the NET and the NPO counted students and days, but each analysis showed that the schools made major advancements.

Some will judge the outcome of this project based on numbers only. We believe that there is a more important outcome. That is, the Pipeline program has moved dental education forward in two critical areas over a short period of time. Students now have a broader understanding of societal issues and greater ability to care for the underserved. Likewise, schools have accepted the need to recruit more diverse students and have changed their recruitment and admissions practices to achieve this goal. In sum, the Pipeline program has had an impact on reducing access disparities through changes in dental education, and as noted in the report, the schools have every intention to sustain these positive changes.

\section{REFERENCES}

1. Andersen RM, Davidson PL, Atchison KA, Crall JJ, Friedman JA, Hewlett ER, Thind A. Summary and implications of the dental pipeline program evaluation. J Dent Educ 2009;73(2 Suppl):S319-S330.

2. Andersen RM, Friedman JA, Carreon DC, Bai J, Nakazono TT, Afifi A, Gutierrez JJ. Recruitment and retention of underrepresented minority and low-income dental students: effects of the pipeline program. J Dent Educ 2009;73(2 Suppl):S238-S258.

3. Oral health in America: a report of the surgeon general. Rockville, MD: U.S. Department of Health and Human Services, National Institute of Dental and Craniofacial Research, National Institutes of Health, 2000. At: www. surgeongeneral.gov/library/oralhealth. Accessed: May 25, 2007.

4. Unequal treatment: confronting racial and ethnic disparities in health care. Washington, D.C.: Institute of Medicine, 2002.

5. Sullivan LW. Missing persons: minorities in the health professions. A report of the Sullivan Commission on diversity in the health care workforce, 2004. At: minorityhealth.pitt.edu/archive/00000040/01/Sullivan_Final_Report_000.pdf. Accessed: September 2008.

6. Bailit HL, Formicola AJ, D'Abreu K, Bau I, Zamora G, Stavisky JS. The dental pipeline program: the national program office perspective. J Dent Educ 2009;73(2 Suppl): S15-S22.

7. In the nation's compelling interest: ensuring diversity in the health care workforce. Washington, DC: Institute of Medicine, 2004. 